\title{
Acoustic Absorption Characteristics of Perforated Thin Plate with Air Jets and Cavity
}

\author{
Hiromitsu Hamakawa1, Hiroki Matsuoka², Taiki Yamai'2, Kenta Asakura ${ }^{3}$, Toru Otsuru ${ }^{4}$, \\ Reiji Tomiku4, Eru Kurihara', Hidechito Hayashi' ${ }^{5}$, Eiichi Nishida ${ }^{6}$ \\ ${ }^{1}$ Department of Mechanical Engineering, Oita University, Oita, Japan \\ ${ }^{2}$ Graduate School, Master's Program of Engineering, Oita University, Oita, Japan \\ ${ }^{3}$ Torishima Pump Mfg. Co., Ltd, Takatsuki-shi, Osaka, Japan \\ ${ }^{4}$ Department of Architecture, Oita University, Oita, Japan \\ ${ }^{5}$ Department of Mechanical Engineering, Nagasaki University, Nagasaki, Japan \\ ${ }^{6}$ Department of Mechanical Systems Engineering, Shonan Institute of Technology, Fujisawa-shi, Kanagawa, \\ Japan \\ Email: hamakawa@oita-u.ac.jp
}

Received 20 January 2015; accepted 8 February 2015; published 12 February 2015

Copyright (C) 2015 by authors and Scientific Research Publishing Inc.

This work is licensed under the Creative Commons Attribution International License (CC BY).

http://creativecommons.org/licenses/by/4.0/

c) (i) Open Access

\begin{abstract}
The present paper focuses on the effect of air jets through a perforated thin plate on the characteristics of an acoustic absorption coefficient. We measured the flow rate, internal pressure, acoustic pressure, and transfer function by using an improved acoustic impedance tube. The normal incidence absorption coefficient was calculated from the measured transfer function using transfer function methods. As a result, the frequency characteristics of the acoustic absorption coefficient against the frequency showed a maximum value at the local frequency. The peak frequency of the acoustic absorption coefficient depended on the thickness of the background air space and the thickness of the perforated plate. As the flow rate increased through the micropores, the peak level of the acoustic absorption coefficient also increased until a flow rate of $80 \mathrm{\ell} / \mathrm{min}$. As the flow rate further increased, the peak level of the acoustic absorption coefficient decreased and that of the high frequency band increased.
\end{abstract}

\section{Keywords}

Acoustic Absorption Coefficient, Perforated Plate, Cavity, Micropores, Air Jets, Acoustic Impedance Tube 


\section{Introduction}

A low noise level and high performance are important features of various kinds of machines. This situation also applies to vehicles, fluid machinery, and fluidic devices. In general, the intensity and frequency of the noise generated from various machines may change because of the operating conditions.

Sound-absorbing material is effective at reducing the reflected and propagation sounds generated from various kinds of machines. However, acoustic absorption effect cannot change regardless of the operating conditions. In addition, sound-absorbing material also has an adiabatic effect. If a machine is covered with a sound-absorbing material, the cooling system must be reset. Therefore, an acoustic device that has both acoustic absorption and cooling effects is needed.

It is believed that acoustic absorption occurs on the surface of micropores from the interaction between the sound waves and the flow. Many studies have been published on the acoustic characteristics of a perforated plate with the flow [1]-[11]. However, it is not clear exactly how the flow through a perforated thin plate affects the characteristics of the acoustic absorption coefficient.

The present paper focuses on the effect of air jets through a perforated thin plate on the thickness of the background air space, the internal pressure, and the plate thickness on the characteristics of the acoustic absorption coefficient. The acoustic characteristics of a measuring system with no air jets are also discussed.

\section{Experimental Apparatus and Procedure}

\subsection{Verification of Measuring System}

Figure 1 shows the basic configuration of an acoustic impedance tube. A loudspeaker is placed at the right side of the tube, and a sample of the test porous material is placed at the opposite side of the tube. The tube length, $L_{1}$, is $710 \mathrm{~mm}$, and its end is terminated by a hard wall. The thickness of the test porous material can be changed to move the hard wall behind the material. A test porous material is enclosed within the test apparatus into which an acoustic wave is emitted from the loudspeaker. The incident sound is white noise of $94 \mathrm{~dB}$ radiated from the loudspeaker connected to the amplifier and function generator. The microphone (B \& K 4187) and measuring amplifier (B \& K 2690-A-OS2) outputs are sampled by a two-channel fast Fourier transform (FFT) analyzer (RION SA-78). The resolution of the two-channel FFT analyzer is set at $1.25 \mathrm{~Hz}$ to measure the transfer function. Linear averaging in the frequency domain is performed 150 times. The normal incidence absorption coefficient is calculated from the measured transfer function by using transfer function methods according to ISO 10534-2.

When the wavelength of the sound source is large enough compared with the width of the cross section of the acoustic impedance tube, the sound field can be modeled in the one-dimensional sound field of the longitudinal direction. In this experiment, the width of the cross section of acoustic impedance tube is $94 \mathrm{~mm}$. At a frequency below approximately $1500 \mathrm{~Hz}$, the wavelength is larger than approximately 2.4 times the width of the cross section. The normal incidence sound absorption coefficient is computed from the measured transfer function using a personal computer. Its measuring range is approximately $100-1500 \mathrm{~Hz}$ for an acoustic impedance tube with an internal cross section of $94 \times 94 \mathrm{~mm}^{2}$.

The experimental apparatus and procedure are verified by measuring the acoustic absorption coefficient of glass wool. Figure 2 shows the typical result of a normal incidence absorption coefficient, $\alpha$, of test glass wool. As the frequency increased, $\alpha$ increased and neared 1.0. The measured absorption coefficient agreed well with the values of open circles measured by using a commercial product impedance tube in Figure 2.

\subsection{Acoustic Absorption Measurement of Perforated Plate with Air Jets}

The acoustic absorption coefficient of a perforated plate with air jets is measured by using an improved acoustic impedance tube, as shown in Figure 3. Two air supply holes were newly installed in acoustic impedance tube. The measurement of the transfer function and the calculation of the acoustic absorption coefficient is the same as the aforementioned case. The air is supplied into the cavity from the two holes connected to the regulator of the compressor. The diameters of the two holes of the air supply port are both $6 \mathrm{~mm}$. When the air supply holes are installed at the upper and lower duct walls, each cross-sectional area of the hole is only approximately $0.3 \%$ of the internal cross-sectional area of $94 \times 94 \mathrm{~mm}^{2}$ in the impedance tube. Thus, the influence of these holes on the acoustic system can be safely ignored. These holes are alternately arranged on the upper and lower sides to 


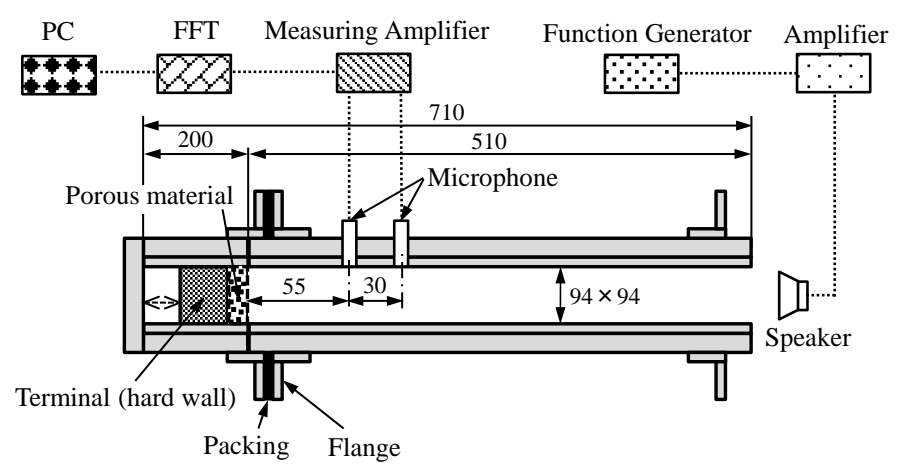

Figure 1. Acoustic impedance tube.

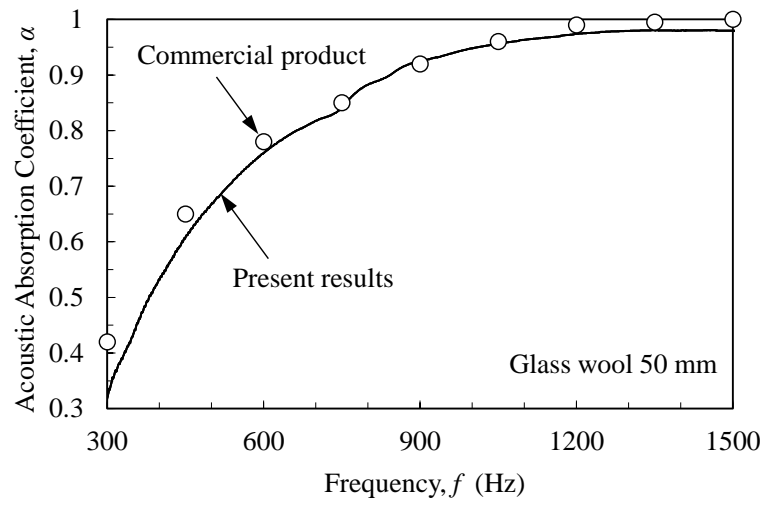

Figure 2. Normal incident absorption coefficient.

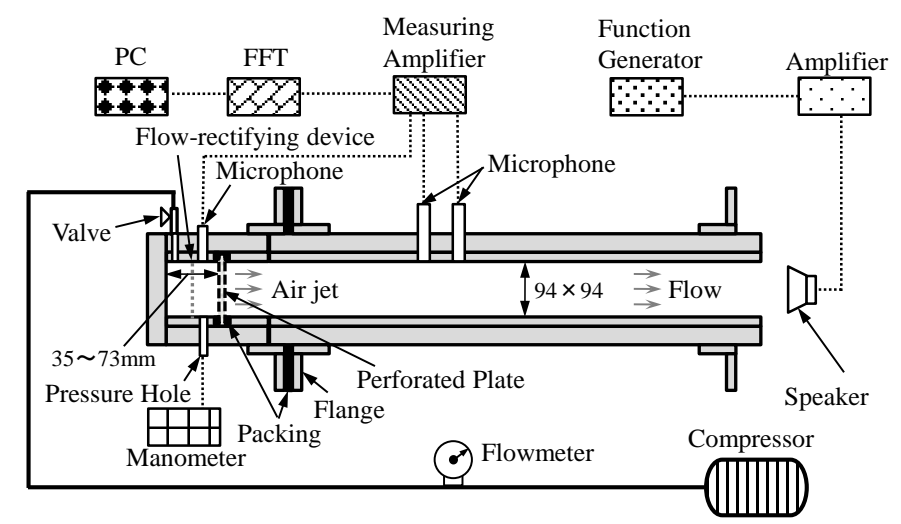

Figure 3. Experimental apparatus.

reduce the interaction noise of the two supply air flows. The incident sound radiated from the loudspeaker is white noise of $94 \mathrm{~dB}$ which is about $20 \mathrm{~dB}$ larger than these supply air flow sound. The air jets are generated by using the perforated thin plate. In the previous experiment, the characteristics of the normal incidence sound absorption coefficient depended on the method of fixing the perforated thin plate in the impedance tube. Here, this perforated thin plate is fixed by being nipped with two soft gaskets in the acoustic impedance tube. The air flow rate is controlled from 0 to $100 \ell / \mathrm{min}$ by a needle valve. The flow-rectifying device, which is a rough porous material with a thickness of $3 \mathrm{~mm}$, is installed at the position where the thickness of the background air space in the perforated plate is $17 \mathrm{~mm}$. This flow-rectifying device does not influence the acoustic absorption coefficient. The thickness of the background air space of the perforated plate is 35, 50,62, and $73 \mathrm{~mm}$. The regulator pressures of the compressor are controlled at $0.15,0.20$, and $0.25 \mathrm{MPa}$. The internal gauge pressure $p_{i}$ in the background air space of the perforated plate is measured with a differential manometer. The Mach number $M$ 
is calculated from the internal pressure $p_{i}$ using the following equation [12]:

$$
\frac{p_{i}}{p_{a}}=\left(1+\frac{\kappa-1}{2} M^{2}\right)^{\kappa /(\kappa-1)}
$$

where $\kappa$ is the heat capacity ratio, $M$ is the Mach number, and $p_{a}$ is atmospheric pressure. The measurement is conducted for periods of $60 \mathrm{~s}$ during the interval of $110 \mathrm{~s}$ in which the flow rate is stable. The uncertainties in $\alpha$ and $p_{i}$ were estimated to be \pm 3 and $\pm 3 \%$, respectively.

Figure 4 shows the geometry of the perforated plate. The diameter of the micropore is $2 \mathrm{~mm}$ and is set up in 64 pieces in the aluminum plate at equal intervals. The thickness of the perforated plates is 1 and $3 \mathrm{~mm}$. The perforated plate is fixed at both sides with packing in the duct. Table 1 shows the experimental conditions in detail.

\section{Results and Discussion}

\subsection{Acoustic Absorption Coefficient of Perforated Thin Plate without Air Jets}

Figure 5 shows the frequency characteristics of the acoustic absorption coefficient of the perforated thin plate without air jets. The perforated thin plate with background air space effectively absorbs sound even though it does not have air jets. As the thickness of the background air space increases, the center frequency of the heap portion of the frequency characteristics decreases. The center frequencies of the heap portion of the frequency characteristics agree well with the frequencies of perforated panel resonator based on the Helmholtz resonator [13]. As shown in the figure, multiple peaks are formed at 138.75, 237.5, 332.5, 418.75, 502.5, and $588.75 \mathrm{~Hz}$ in the frequency characteristics of the acoustic absorption coefficient. These frequencies do not depend on the thickness of the background air space.

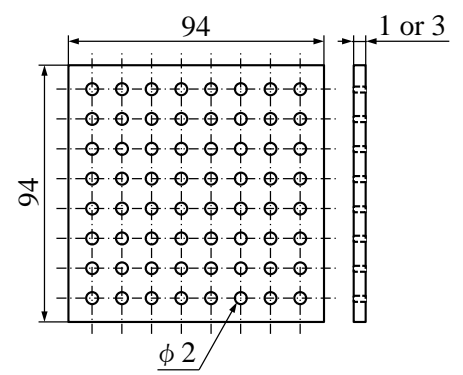

(a)

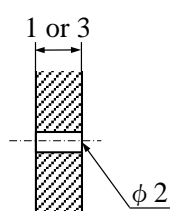

(b)

Figure 4. Geometry of perforated plate. (a) Shape of perforated plate; (b) Shape of micropore.

\begin{tabular}{ccc} 
Table 1. Experimental conditions & \\
\hline \multicolumn{2}{c}{ Improved acoustic impedance tube } \\
\hline Cross-sectional area & $A$ & $94 \times 94 \mathrm{~mm}^{2}$ \\
Volume flow rate & $Q$ & $0-100 \mathrm{\ell} / \mathrm{min}$ \\
Thickness of background air space & $L$ & $35,50,62$, and $73 \mathrm{~mm}$ \\
Tube length without perforated plate & $L_{1}$ & $710 \mathrm{~mm}$ \\
Regulator pressure & $p$ & $0.15,0.20$, and $0.25 \mathrm{MPa}$ \\
\hline \multicolumn{2}{c}{ Perforated plate } \\
\hline Plate thickness & $t$ & 1, and $3 \mathrm{~mm}$ \\
Number of micropores & $N$ & 64 \\
Diameter of micropores & $d$ & $2 \mathrm{~mm}$ \\
Opening ratio of micropores & $\sigma$ & $2.28 \%$ \\
\hline
\end{tabular}


Figure 6 shows the results of the thin plate with a thickness of $1 \mathrm{~mm}$ without micropores. A single high peak is formed at $506.25 \mathrm{~Hz}$ in the frequency characteristics of the acoustic absorption coefficient. It is believed that this is caused by panel vibration, such as the panel sound absorber. However, no peak is observed in the case of the thin plate with a thickness of $3 \mathrm{~mm}$ without micropores.

Next, the micropores of the perforated thin plate are closed with polyvinylidene chloride (PVDC) film. Figure 7 shows the result of the perforated thin plate with PVDC film with no air jets. No peak is observed in the case of the perforated thin plate with a thickness of $3 \mathrm{~mm}$. The perforated thin plate covered with PVDC film does not effectively absorb sound. The acoustic absorption coefficient does not increase due to panel vibration.

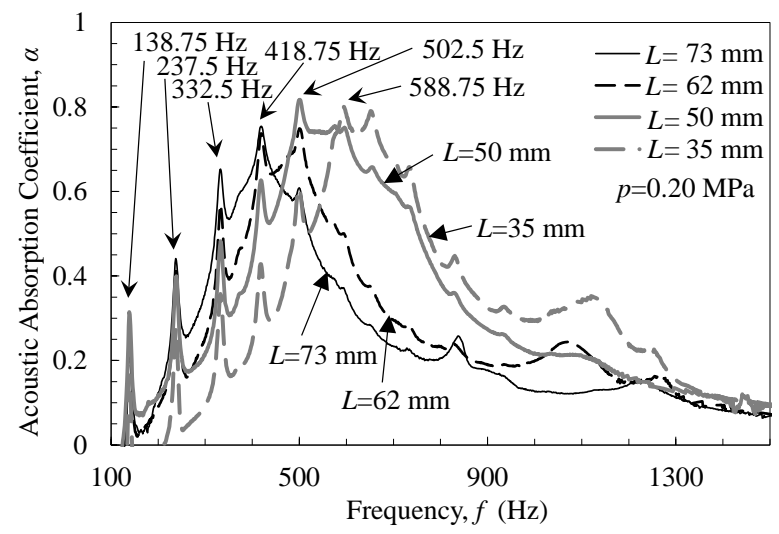

Figure 5. Acoustic absorption coefficient without air jets.

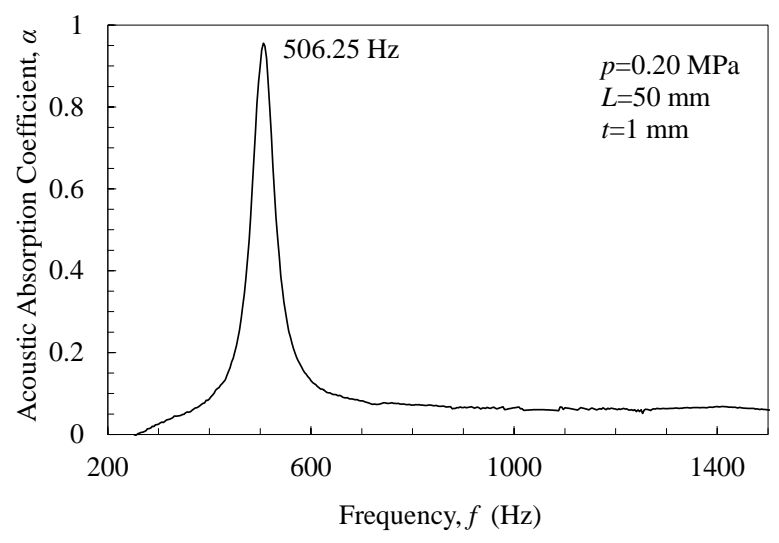

Figure 6. Acoustic absorption coefficient with no micropores.

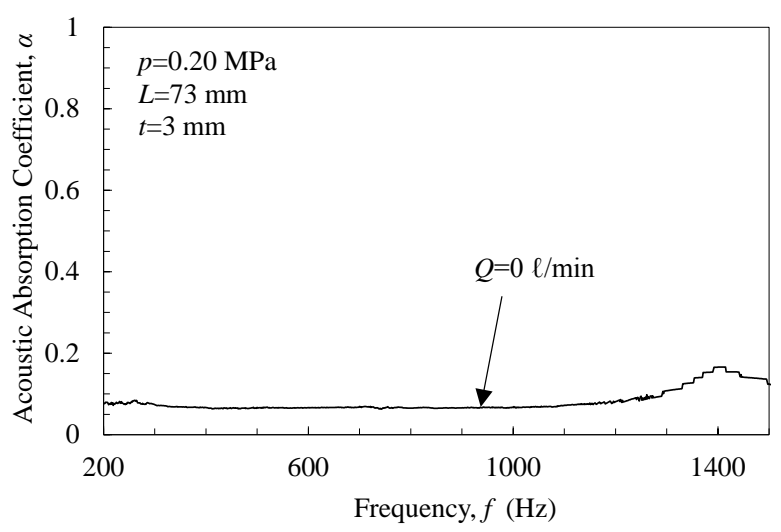

Figure 7. Acoustic absorption coefficient of perforated thin plate with PVDC film. 
The natural frequency of the perforated plate fixed inside the acoustic tube, which is measured by a hammering test, is approximately $100 \mathrm{~Hz}$. It is believed that the multiple peaks of the frequency characteristics in Figure 5 is not caused by panel vibration.

The resonance curve is measured by supplying a pure tone from the loudspeaker. The measured resonant frequencies reach approximately $110 \mathrm{~Hz}, 330 \mathrm{~Hz}, 550 \mathrm{~Hz}$, and $770 \mathrm{~Hz}$. The acoustic resonant frequency in the streamwise direction of the acoustic impedance tube is given by

$$
f=\frac{(2 n-1) c}{4 L_{1}}
$$

where $c$ is the sound velocity, $L_{1}$ is the length of the acoustic tube, and $n$ is the number of longitudinal standing waves in the acoustic tube. The acoustic natural resonant frequencies in the stream wise direction of the acoustic impedance tube are $110 \mathrm{~Hz}(n=1), 329 \mathrm{~Hz} \quad(n=2), 549 \mathrm{~Hz} \quad(n=3)$, and $768 \mathrm{~Hz} \quad(n=4)$ when the duct length is $710 \mathrm{~mm}$ and the temperature of the flow is $22^{\circ} \mathrm{C}$. These values, which agreed well with the measured results, are not in agreement with the multiple peaks in Figure 5. The reason for the multiple peaks of the frequency characteristics of the acoustic absorption coefficient is not clear. Further investigation is needed to clarify the exact reason for these multiple peaks.

\subsection{Acoustic Absorption Coefficient of Perforated Plate with Air Jets}

Figure 8 shows the frequency characteristics of the acoustic absorption coefficient. In Figure 8(a), the six relative volume flow rates, $Q$, are shown as parameters from 0 to $100 \mathrm{\ell} / \mathrm{min}$. As the flow rate increases, the acoustic absorption coefficient also increases at a wide frequency range until $Q=80 \mathrm{l} / \mathrm{min}$. The acoustic absorption coefficient nears 1.0 at $Q=80 \mathrm{l} / \mathrm{min}$ and $f=480 \mathrm{~Hz}$. The six relative volume flow rates are shown as parameters from 50 to $100 \mathrm{l} / \mathrm{min}$ in detail in Figure 8(b). As the flow rate further increases, the peak level of the acoustic absorption coefficient decreases, although the acoustic absorption coefficient over $570 \mathrm{~Hz}$ also increases.

Figure 9 shows the frequency characteristics of the acoustic absorption coefficient, $\alpha$, at four relative thicknesses, $L$, of the background air space of the perforated plate. As the thickness of the background air space increases, the peak frequency decreases. The distribution profile of the frequency characteristics of acoustic absorption coefficient does not change even if the flow rate increases. The frequency of the acoustic absorption coefficient depends on the thickness of the background air space.

Figure 10 compares the frequency characteristics of the plate thickness, $t$, of $3 \mathrm{~mm}$ and $1 \mathrm{~mm}$. The acoustic absorption coefficient of $t=1 \mathrm{~mm}$ is increased rather than that of $t=3 \mathrm{~mm}$ at the wider frequency range, although the thicknesses of the background air space $L$ is constant at $73 \mathrm{~mm}$ and the frequency of the panel vibration is constant at approximately $506.25 \mathrm{~Hz}$. Furthermore, the frequency at the maximum acoustic absorption coefficient of $t=1 \mathrm{~mm}$ is larger than that of $t=3 \mathrm{~mm}$. The frequency of the acoustic absorption coefficient depends on not only the thickness of the background air space but also the plate thickness of the perforated plate.

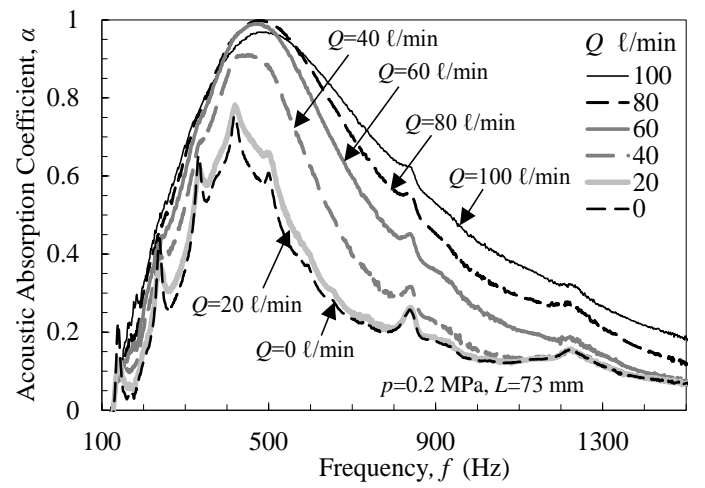

(a)

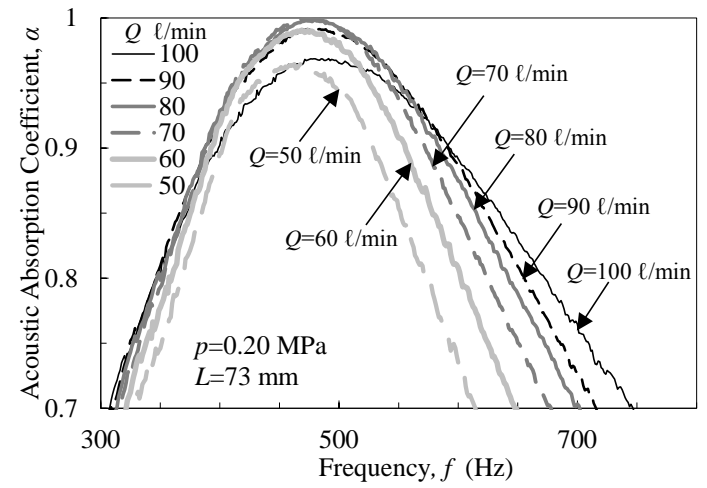

(b)

Figure 8. Effect of volume flow rate on acoustic absorption coefficient. (a) $Q=0-100 \mathrm{\ell} / \mathrm{min}$; (b) $Q=50-100$ $\ell / \min$. 


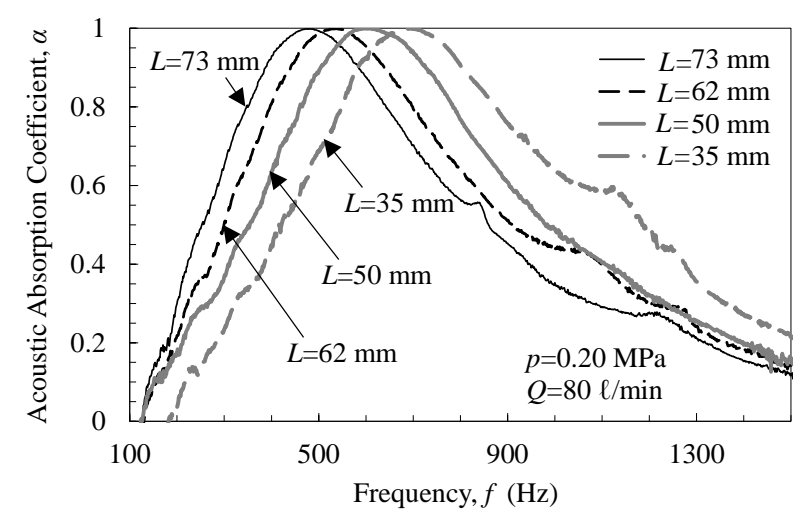

Figure 9. Effect of background space on acoustic absorption coefficient.

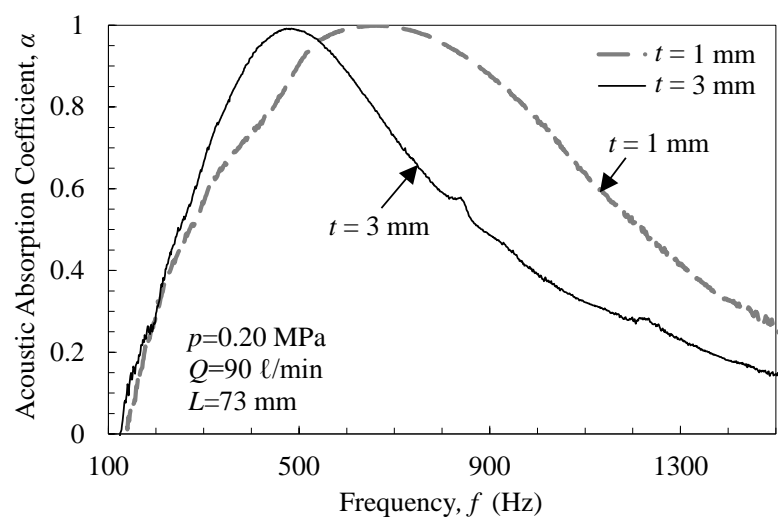

Figure 10. Effect of plate thickness on acoustic absorption coefficient.

Next, we measure the frequency characteristics of the acoustic absorption coefficient at three relative regulator pressures $p$ of $0.15,0.20$, and $0.25 \mathrm{MPa}$. Figure 11 shows the frequency characteristics of the acoustic absorption coefficient. The frequency characteristics of the acoustic absorption coefficient do not change, although the regulator pressures change. Figure 12 shows the internal pressure $p_{i}$ inside the cavity against the regulator pressure $p$. The internal pressures of the cavity for different regulator pressures reach almost the same values. The Mach number $M$ is calculated from the internal pressure $p_{i}$ using Equation (1). Table 2 shows the Mach number and the mean velocity of the micropore. The Mach numbers are small, and the mean velocity of the micropore does not exceed the speed of sound. The relation between the increase of the acoustic absorption coefficient and the jets flow through the micropores is not clear. Further investigation is needed to clarify the reasons for the increase of the acoustic absorption coefficient in the case with air jets.

\section{Conclusions}

The effects of air jets through a perforated thin plate on the frequency characteristics of an acoustic absorption coefficient were experimentally investigated. As a result, the following conclusions were obtained:

1) As the flow rate increased through the micropores, the peak level of the acoustic absorption coefficient increased until a flow rate of $80 \mathrm{l} / \mathrm{min}$. As the flow rate further increased, the peak level of the acoustic absorption coefficient decreased and that of the high frequency band increased.

2) The frequency characteristics of the acoustic absorption coefficient showed a maximum value at the local frequency. As the thickness of the background air space increased, the peak frequency decreased. The peak frequency of the acoustic absorption coefficient depended on the thickness of the background air space and the thickness of the perforated plate.

3) The acoustic absorption coefficient with a plate thickness of $1 \mathrm{~mm}$ increased at a wider frequency range 


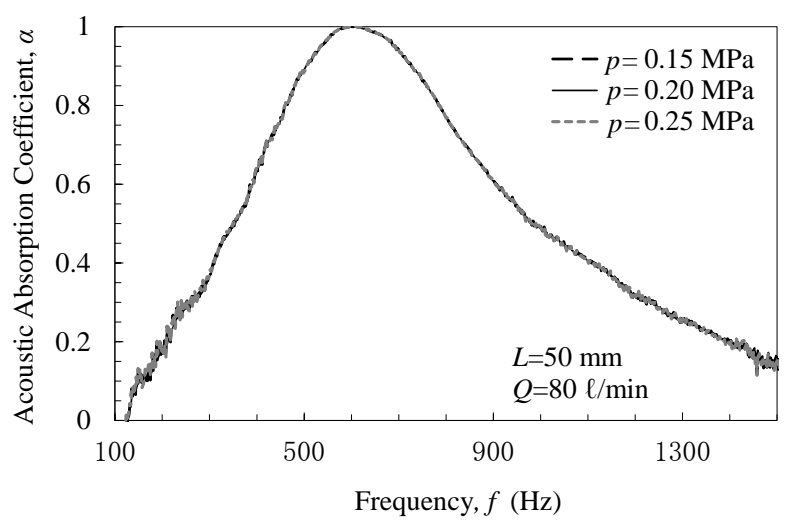

Figure 11. Effect of regulator pressure on acoustic absorption coefficient.

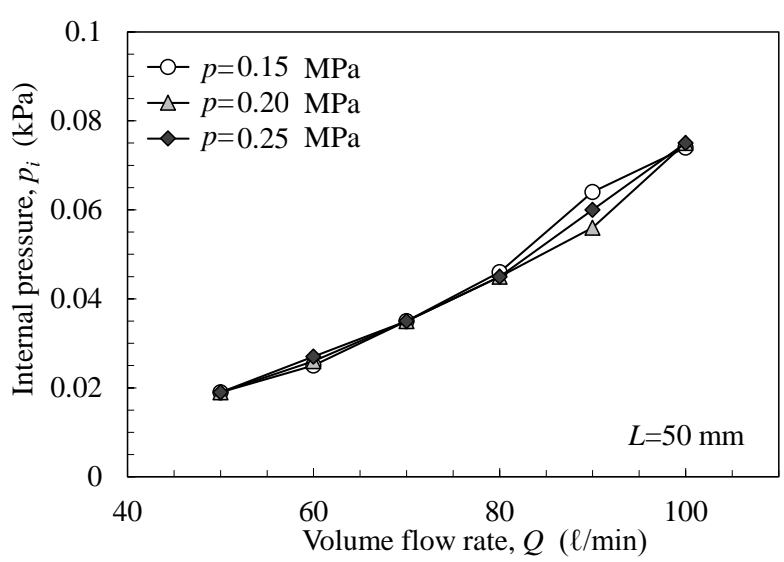

Figure 12. Internal pressure in the cavity against volume flow rate.

Table 2. Mean flow velocity in the micropore.

\begin{tabular}{cccc}
\hline Volume flow rate & Internal pressure & Mach number & Mean velocity of micropore \\
\hline$Q(\ell / \mathrm{min})$ & $p_{i}(\mathrm{kPa})$ & $M$ & $v(\mathrm{~m} / \mathrm{s})$ \\
\hline 50 & 0.019 & 0.016 & 5.6 \\
60 & 0.027 & 0.020 & 6.7 \\
70 & 0.035 & 0.022 & 7.6 \\
80 & 0.045 & 0.025 & 8.6 \\
90 & 0.060 & 0.029 & 10.0 \\
100 & 0.075 & 0.033 & 11.2 \\
\hline
\end{tabular}

than that of the thickness of $3 \mathrm{~mm}$, although the thicknesses of the background air space of the perforated plate were constant. The frequency of the acoustic absorption coefficient depended on the plate thickness.

4) The internal pressures of the cavity for different regulator pressures reached almost the same values. The frequency characteristics of the acoustic absorption coefficient did not depend on these pressures.

\section{Acknowledgements}

The work was partially supported by the Grant-in-Aid for Scientific Research No. 26420178 from the Japan Society for Promotion of Science (in the Japan Ministry of Education and Science) and the Research Grant from 
Harada Commemorative Foundation for which the authors wish to express their sincere gratitude.

\section{References}

[1] Howe, M.S. (1979) On the Theory of Unsteady High Reynolds Number Flow through a Circular Aperture. Proceedings of the Royal Society London, Series A, 366, 205-223. http://dx.doi.org/10.1098/rspa.1979.0048

[2] Hughes, I.J. and Dowling, A.P. (1990) The Absorption of Sound by Perforated Linings. Journal of Fluid Mechanics, 218, 299-335. http://dx.doi.org/10.1017/S002211209000101X

[3] Dowling, A.P. and Hughes, I.J. (1992) Sound Absorption by a Screen with a Regular Array of Slits. Journal of Sound Vibration, 156, 387-405. http://dx.doi.org/10.1016/0022-460X(92)90735-G

[4] Jing, X. and Sun, X. (1999) Experimental Investigation of Perforated Liners with Bias Flow. The Journal of the Acoustical Society of America, 106, 2436-2441. http://dx.doi.org/10.1121/1.428128

[5] Jing, X. and Sun, X. (2000) Effect of Plate Thickness on Impedance of Perforated Plates with Bias Flow. AIAA Journal, 38, 1573-1578. http://dx.doi.org/10.2514/2.1139

[6] Dupere, I.D.J. and Dowling, A.P. (2002) The Absorption of Sound by Helmholtz Resonators with and without Flow. American Institute of Aeronautics and Astronautics, 2002-2590. http://arc.aiaa.org/doi/abs/10.2514/6.2002-2590

[7] Luong, T., Howe, M.S. and McGowan, R.S. (2005) On the Rayleigh Conductivity of a Bias-flow Aperture. Journal of Fluids and Structure, 21, 769-778. http://dx.doi.org/10.1016/j.jfluidstructs.2005.09.010

[8] Wada, K., Ishii, T. and Morimoto, J. (2012) Acoustic Absorption Characteristics of Sound Waves Interacting with Fine-Scale Jets. 2012 Symposium on Environmental Engineering, No. 12-6, No. 122.

[9] Scarpato, A., Tran, N., Ducruix, S. and Schuller, T. (2012) Modeling the Damping Properties of Perforated Screens Traversed by a Bias Flow and Backed by a Cavity at Low Strouhal Number. Journal of Sound and Vibration, 331, 276-290. http://dx.doi.org/10.1016/j.jsv.2011.09.005

[10] Wada, K. and Ishii, T. (2013) Acoustic Absorption of Perforated Plates with Fine Jets: Experimental Results and Analytical Models. Proceedings of 4th International Conference on Jets, Wakes and Separated Flows, Nagoya, 17-21 September 2013, Paper No. ICJWSF2013-1127.

[11] Scarpato, A., Ducruix, S. and Schuller, T. (2013) Optimal and Off-Design Operations of Acoustic Dampers Using Perforated Plates Backed by a Cavity. Journal of Sound and Vibration, 332, 4856-4875. http://dx.doi.org/10.1016/j.jsv.2013.03.030

[12] White, F.M. (1994) Fluid Mechanics. Third Edition, McGraw Hill, Boston.

[13] Vigran, T.E. (2008) Building Acoustics. CRC Press, Boca Raton.

\section{Nomenclature}

$c$ : Sound velocity $(\mathrm{m} / \mathrm{s})$;

$f$ : Frequency $(\mathrm{Hz})$;

$L$ : Thicknesses of the background air space (mm);

M: Mach number;

$p$ : Regulator pressure $(\mathrm{Pa})$;

$p_{a}$ : Atmospheric pressure $(\mathrm{Pa})$;

$p_{i}$ : Internal pressure $(\mathrm{Pa})$;

$Q$ : Volume flow rate $(\ell / \mathrm{min})$;

$t$ : Plate thickness (mm);

$\alpha$ : Normal incidence absorption coefficient;

$\kappa$ : Heat capacity ratio. 
Scientific Research Publishing (SCIRP) is one of the largest Open Access journal publishers. It is currently publishing more than 200 open access, online, peer-reviewed journals covering a wide range of academic disciplines. SCIRP serves the worldwide academic communities and contributes to the progress and application of science with its publication.

Other selected journals from SCIRP are listed as below. Submit your manuscript to us via either submit@scirp.org or Online Submission Portal.
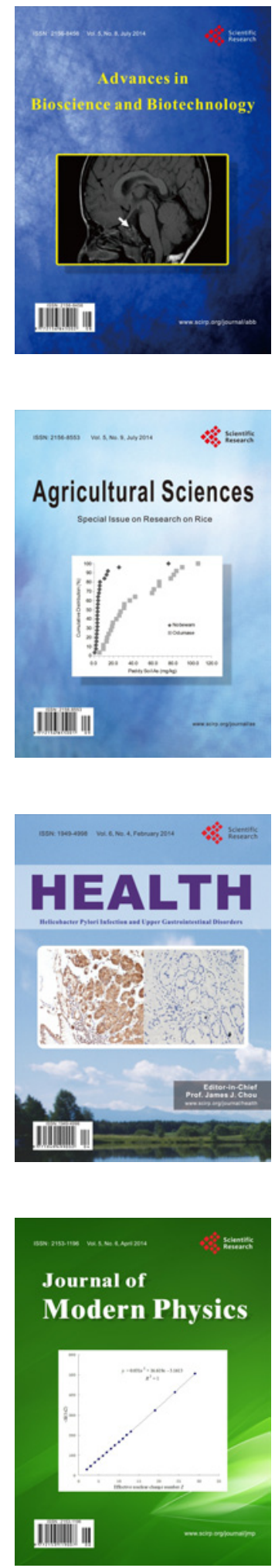
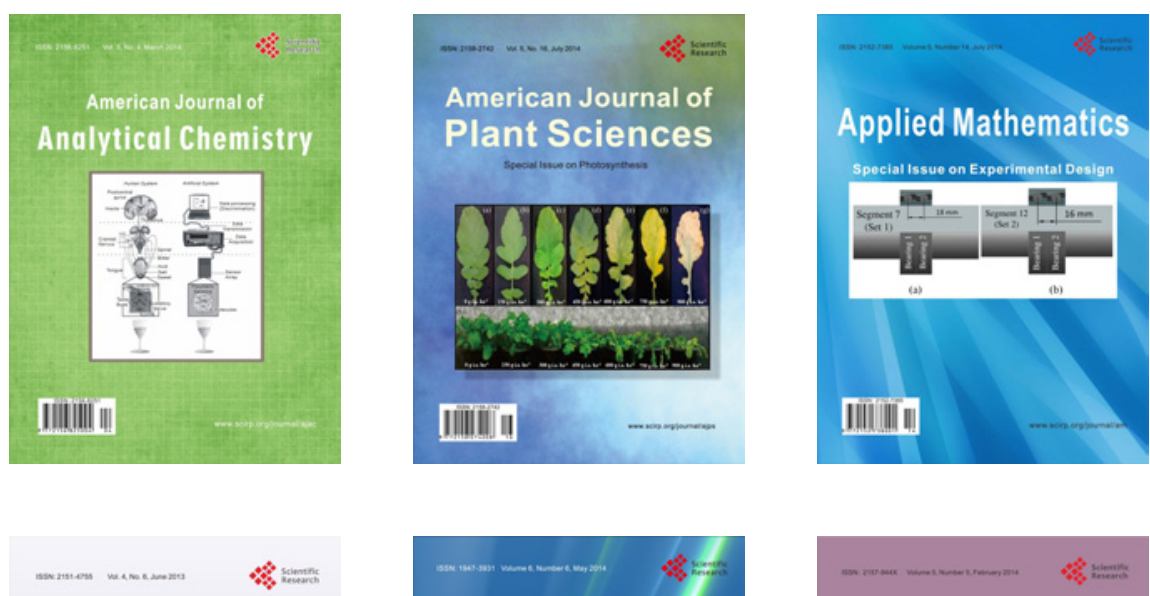

Creative Education
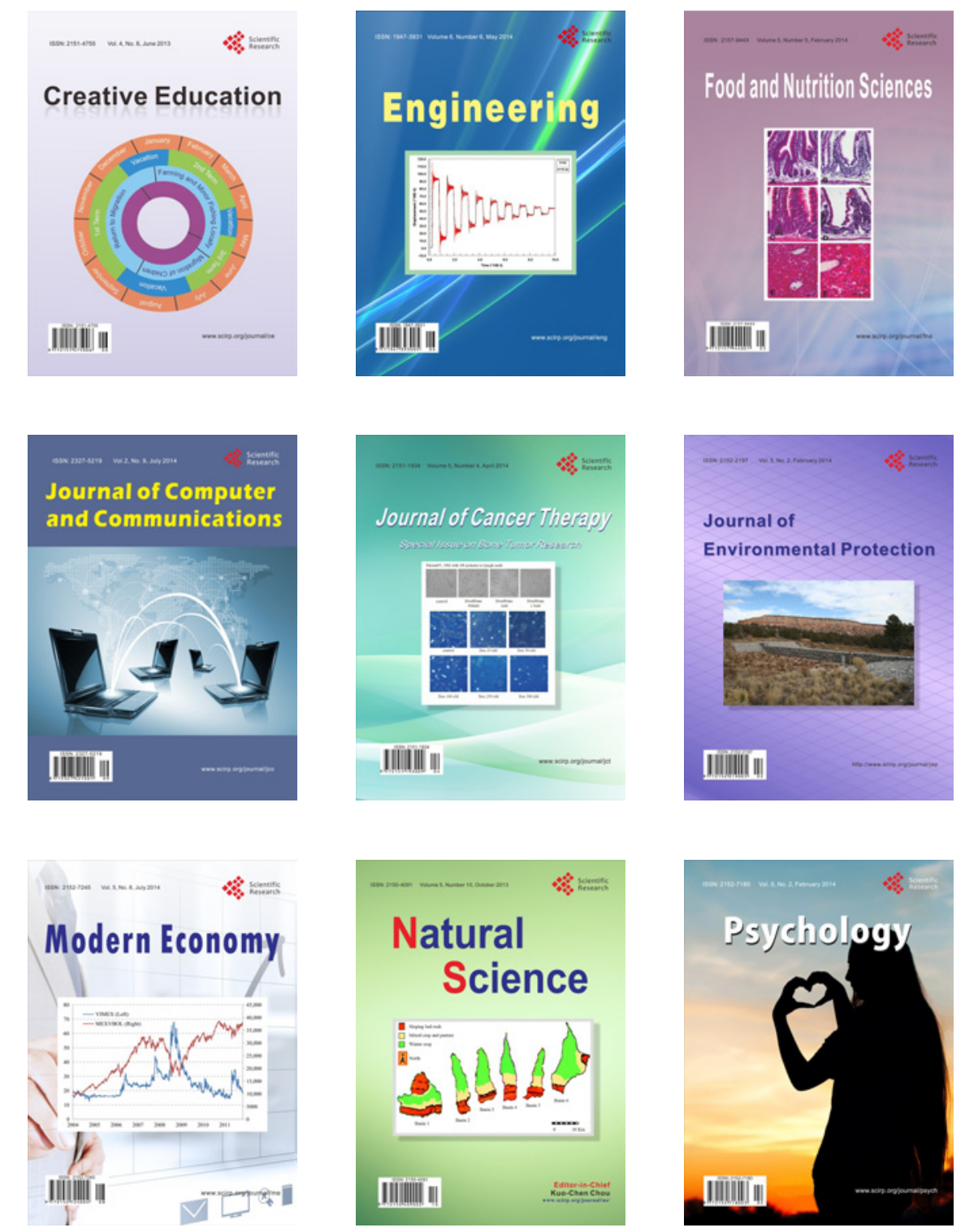